\title{
Using the Multi Criteria Decision Making Methods in Aircraft Selection Problems and an Application
}

\author{
Kasım Kiracı | Department of Aviation Management, School of Civil Aviation, Iskenderun Technical University, Turkey, \\ kasim.kiraci@iste.edu.tr
}

Mahmut Bakır | Department of Aviation Management, Faculty of Aeronautics and Astronautics, Anadolu University, Turkey, mahmutbakir@anadolu.edu.tr

\begin{tabular}{ll}
\hline $\begin{array}{l}\text { Keywords: } \\
\text { Airline }\end{array}$ & $\begin{array}{l}\text { This study focuses on the choice of aircraft, which is one of the rarely studied topics in the literature. The aim of the } \\
\text { work is to determine the most suitable aircraft for airline companies with different flight networks and different } \\
\text { flight different destination. The aim of the study is to determine the most suitable aircraft type among aircraft type } \\
\text { alternatives, based on the criteria determined by the opinions of industry experts. In the study, it was aimed to } \\
\text { determine the most suitable alternative among the four aircraft types which are hava most demand by airline } \\
\text { companies by using the TOPSIS method. Findings of the study show that the most suitable type of aircraft } \\
\text { according to the TOPSIS method is B737-800. }\end{array}$ \\
\hline
\end{tabular}

\section{Havaaracı Seçim Problemlerinde Çok Kriterli Karar Verme Yöntemlerinin Kullanılması ve}

\section{Bir Uygulama}

\section{öz}

Anahtar Sözcükler :

Havayolu

Uçak Seçimi

TOPSIS Yöntemi
Bu çalışmada, literatürde nadiren çalışılan konulardan biri olan uçak seçimi üzerine odaklanılmıştır. Çalışmanın amacı, farklı uçuş ağına ve uçuş noktasına sahip havayolu şirketleri açısından en uygun hava aracının belirlenmesidir. Çalışmada, sektör uzmanlarının görüşleri doğrultusunda belirlenen kriterler esas alınarak, uçak tipleri alternatifleri arasında en uygun uçak tipinin belirlenmesi hedeflenmektedir. Çalışmada, havayolu şirketleri tarafından en fazla talep gören 4 uçak tipi arasından en uygun alternatifin TOPSIS yöntemi kullanılarak belirlenmesi amaçlanmıştır. Çalışmanın bulguları TOPSIS yöntemine göre en uygun havaaracı tipinin B737-800 olduğunu göstermektedir.

\section{Cite this article as}

Kiracı, K. \& Bakır, M. (2018). Havaaracı Seçim Problemlerinde Çok Kriterli Karar Verme Yöntemlerinin Kullanılması ve Bir Uygulama. Journal of Transportation and Logistics, 3(1), 13-24. doi: 10.26650/JTL.2018.03.01.02 


\section{Extended Abstract}

\section{Using the Multi Criteria Decision Making Methods in Aircraft Selection Problems and an Application}

Research Problem: This study focuses on the selection of commercial aircraft, which is extremely important for airline companies. In this context, the performance of four different types of aircraft which are most demanded by airline companies (ordered) in 2016 and which can be used on short and medium haul flights have been evaluated. In the performance evaluation, a number of selection criteria were determined in line with the opinions of the sector experts and these criteria were weighted in the direction of expert opinions. In the rest of the study, selected aircraft types were analyzed using the TOPSIS (Technique for Order Performance by Similarity to Ideal Solution) method according to selection criteria and the aircraft with the best performance was identified.

Research Question: In this study, which deals with the selection of the most ordered and short- and medium haul aircrafts, the research question is which type of aircraft is best according to the selection criteria. The performance indicators considered as the selection criteria in the study were determined as aircraft range, aircraft price, speed, passenger capacity and fuel consumption. This study is considered to be complementary to the literature both in terms of the aircraft being evaluated and the measurement indicators that are determined.

Methodology: The analysis of this study was carried out in two stages. In the first stage, a number of measurement criteria have been set in the direction of expert opinions working in the aviation sector and these criteria have been weighted by the same experts according to their level of importance. In the second stage, four types of aircraft are listed in the literature through TOPSIS (technique for order performance by similarity to ideal solution) method which is frequently used in performance measurement. The evaluation criteria were obtained from the documents of aircraft manufacturing companies and sectoral reports. The TOPSIS method used in the study was first developed by Hwang and Yoon (1981). This method is one of the most used multi-criteria decision making (MCDM) methods in the literature. In the TOPSIS method, the alternatives are evaluated according to ideal conditions between the minimum and maximum values that can be taken by certain criteria. The TOPSIS method is used in decision making problems involving quantitative data. At the basis of TOPSIS lies the principle that the best alternative is to find the ideal ideal solution at the nearest distance and the negative ideal solution at the farthest distance.

Results and Conclusions: In this study, A320, A321, B737-800 and B737-900ER planes, which can be used for short and medium haul flights and are most ordered aircrafts in 2016 were taken as decision alternatives. Expert opinions were taken in the first stage and analysis was carried out in the second stage using the TOPSIS method. Among the four types of aircraft included in the analysis, the most appropriate type of aircraft was determined for airline companies according to the criteria specified. The results of the study show that the most suitable aircraft type is B737-800. After B737-800, the most suitable alternative is B737-900ER, while A321 is the third and $A 320$ is the last one. Based on the criteria and aircraft type alternatives, it is expected that this study will guide airline companies on the selection of aircraft. Considering the methods applied in the study, it is expected that different results will be obtained if different criteria or different types of aircraft are added. Therefore, airline companies can choose the most suitable aircraft among different alternatives using these methods according to their flight networks and priorities. This study is expected to contribute to the airline's operations in this respect. 


\section{Giriş}

Havayolu endüstrisi, rekabetin en çok yaşandığı sektörlerden biri konumunda bulunmaktadır. Havayolu kapasitesinin yüksek yolcu sayısının düşük kaldığı durumlarda arz ve talep arasındaki dengenin sağlanması havayolu şirketlerinin kaynaklarını etkin ve verimli kullanmalarıyla doğrudan ilişkilidir. Rekabet ortamında mevcut kaynaklarını etkin ve verimli bir şekilde kullanmaya zorlanan havayolu şirketleri açısından filo planlanmasının doğru yapılması ve uygun uçak tipinin seçilmesi en kritik konulardan biri olarak karşımıza çıkmaktadır. Diğer bir anlatımla, havayolu şirketlerinin uçak seçiminde birçok ölçüte göre hareket etmesi ve doğru uçak seçiminde bulunması onun diğer havayollarına göre stratejik rekabet avantajı elde etmesine olanak sağlayabilir. Dolayısıyla havayolu şirketlerinin kendi ihtiyaçları doğrultusunda en uygun uçak tipinin hangisi olduğunun doğru bir şekilde belirlemesi daha düşük maliyet ve daha yüksek potansiyele sahip olmasına zemin hazırlayabilir.

Havayolu şirketlerinin doğru filo yapısına sahip olması ve uçak tipi seçimlerini uygun bir şekilde belirlemesi aynı zamanda değişen piyasa koşullarına daha hızlı bir şekilde adapte olmasına ve ihtiyaçları karşılayabilecek uygun çözümlere ulaşılmasını sağlayabilir. Havayolu şirketlerinin çok sayıda değerlendirme kriterini bir arada dikkate alarak uçak alternatifleri arasında en uygun uçak tipi seçimini doğru bir şekilde yapması, sektörün sahip olduğu kaynakların etkin bir şekilde kullanılmasına olanak sağladığı gibi çevresel ve ekonomik kaynakların etkin ve verimli bir şekilde kullanılmasına olanak sağlamaktadır. Bu durum aynı zamanda firmaların kapasite, hız, performans, kârlılık ve maliyet gibi birçok kriter arasında en doğru seçimi yapmasına zemin hazırlamaktadır.

Bu çalışma temel olarak 5 bölümden oluşmaktadır. Çalışmanın ikinci bölümünde uçak tipi seçimini esas alan çalışmalara yer verilecektir. Çalışmanın 3. bölümünde çalışma kapsamında tercih edilen çok kriterli karar verme yöntemlerinden TOPSIS yöntemi ayrıntılı bir şekilde tanıtılacaktır. Çalışmanın 4. bölümünde uçak seçiminde belirlenen kriterler ve uçak tipleri hakkında bilgi verilecek ve çalışmanın ampirik uygulamasına yer verilecektir. Çalışmanın son bölümünde ise elde edilen bulgular ampirik değerlendirilecek ve havayolu şirketleri açısından en uygun uçak tiplerinin bilgisine yer verilecektir.

\section{Literatür Özeti}

Literatürde en uygun hava aracı seçimi konusunda birçok çalışma yapılmıştır. Bu çalışmaların bir kısmında, farklı senaryolar altında "en iyi performans" gösteren havaaraçlarının incelendiği görülmektedir (Teoh ve Khoo, 2015; Listes ve Dekker, 2005; Khoo ve Teoh, 2014). Bazı çalışmalarda ise, hava kirliliği, iklim değişikliği ve gürültü gibi çevre özellikleri dikkate alınarak, en uygun havaaracının belirlenmesi konusuna odaklanılmıştır (Givoni ve Rietveld, 2010). Buna ek olarak, teknik yapıları ve finansal maliyetlileri dikkate alınarak hava araçlarının karşılaştırıldığı çalışmalara da rastlanmaktadır (Gomes, 2014). Uygun havaaraçlarının belirlenmesine yönelik çalışmaların yanı sıra, filo atama problemleri/uygun filo yapısının belirlenmesine yönelik çalışmaların da yapıldığı görülmektedir (Sherali vd., 2006; Bhadra, 2003).

Literatürde genel itibariyle, uçuş mesafesi ve uçuş merkezi esas alınarak ya da hava araçlarının teknik ve fiziki özelliklerinden hareketle "en iyi performansa sahip" 
uçakların belirlenmeye çalışıldığı görülmektedir. Örneğin; Harasani (2006), Suudi Arabistan'da Cidde merkezli faaliyet gösteren bir havayolu şirketi açısından, hem yerel hem de uluslararası uçuş ağına en uygun uçak filosunu incelemiştir. Bu kapsamda, 10 farklı uçuş noktası için 6 uçak tipi, sahip oldukları teknik özelliklere ve maliyet göstergelerine göre listelenmiştir. Çalışmada, en uygun uçak tiplerinin esas alınan değişkene göre farklıık gösterdiği ancak, EMB145 tipi uçakların ele alınan güzergahta en fazla katkıyı sağlayacağı vurgulanmıştır. Wang ve Chang (2007), Tayvan Hava Kuvvetleri Akademisi açısından en uygun başlangıç eğitim uçaklarının belirlenmesi amacıyla TOPSIS yöntemine dayanan bir değerlendirme yaklaşımı geliştirmiştir. Bu doğrultuda, 7 pervaneli uçak tipi, 16 farklı kritere değerlendirilmiştir. Çalışmanın sonuçları, KT-1 tipi pervaneli uçağın 7 eğitim uçağı arasında en iyi özelliklere sahip olduğunu göstermiştir. Ozdemir vd. (2011), çok kriterli karar verme tekniklerinden biri olan Analitik Ağ Süreci (ANP) yaklaşımını kullanarak, Türk Hava Yolları açısından satın alınacak uçaklar için, belli kriterler göz önünde bulundurularak hangi uçakların tercih edilmesi gerektiği incelemiştir. Bu kapsamda, belirlenen 3 uçak tipine ilişkin, maliyet, zaman ve fiziki özellikler gibi ana kriterleri ve bunlara bağlı alt kriterler dikkate alınarak en uygun uçak tipinin belirlenmiştir. Çalışmada orta menzile sahip, standart gövdeli ve tek koridorlu 3 farklı uçak tiplerinin karşılaştırıldığı görülmektedir. Çalışmanın bulguları, Türk Hava Yolları açısından en uygun havaaracının B737 olduğunu göstermektedir. Dožić ve Kalić (2014), belirli uçuş ağlarında ve havayoluna olan talebin öngörülebildiği hatlarda, havayolu şirketlerinin uçak seçim problemlerini Analitik Hiyerarşi Prosesi (Analytic Hierarchy Process) yöntemini kullanarak çözmeyi amaçlamaktadır. Bu kapsamda farazi olarak, Güneydoğu Avrupa'da faaliyet gösteren ve 27 uçuş noktasına sahip bir havayolu firması açısından, en uygun uçak seçiminin ne olması gerektiği incelenmiştir. Çalışmada 7 farklı uçak tipi için, kapasite, fiyat, toplam bagaj hacmi, MTOW (maximum take-off weight), ödeme koşulları ve CASM (total cost per available seat miles) gibi özellikler dikkate almıştır. Çalışmanın bulguları, özellikle faaliyet giderleri esas alındığında, turboprop ATR 72-600 uçak tipinin havayolu şirketleri açısından en uygun seçim olabileceğini ortaya koymaktadır.

Bruno vd. (2015), havayollarının uçak seçimine yönelik ihtiyaçlarından hareketle, uçak değerlendirmesi için yeni bir model geliştirmiştir. Bu kapsamda uçaklara iliş̧kin, ekonomik performans, teknik performans, uçak iç kalitesi ve çevreye etki gibi bir takım ana kriterler ve bunlara bağlı alt kriterlere belirlenmiştir. Analitik Hiyerarşi Prosesi (AHP) ve Bulanık Küme Teorisi yöntemlerinin uygulandığı çalışmada, 3 farklı uçak tipi değerlendirilmiştir. Çalışmanın sonuçları, en yüksek değerlendirme skoruna sahip uçak tipinin Sukhoi SSJ 1000 olduğunu göstermiştir. Dožić ve Kalić (2015), kısa ve uzun menzilli uçuş gerçekleştiren havayolu şirketlerinin filo büyüklüğü ve filo yapısı sorunlarıyla ilgili bir model geliştirmiştir. Bu kapsamda, Belgrad Havalimanının merkez olarak alındığı ve bu havalimanından kısa ve orta menzilli toplam 27 noktaya uçuş gerçekleştirildiği varsayımından hareketle uçak ve filo seçimine yönelik bir model geliştirilmiştir. Uçak tipi seçim aşamasında küçük ve orta büyüklükteki uçaklar, kapasite, fiyat, yolcu başına bagaj hacmi, MTOW (maximum take-off weight) ve birim maliyet (c/ASM) dikkate alınarak belirlenmiştir. Analitik Hiyerarşi Prosesi (Analytic Hierarchy Process) yönteminin kullanıldığı çalışmada, kısa menzilli uçuşlarda ATR 72600 tipi, orta menzilli uçuşlarda ise A319neo tipi uçakların, havayolu şirketleri açısından en iyi seçenek olduğu sonucuna ulaşılmıştır. Özdemir ve Başlıgil (2016), Türk Hava Yolların tarafından satın alınan uçakları, farklı kriterlere göre değerlendirerek en uygun uçak seçiminin hangisi olduğunu tespit etmeyi amaçlamıştır. Bu kapsamda, çok 
kriterli karar verme teknikleri olan bulanık ANP ve Choquet integral yöntemleri kullanılmış ve bu yöntemlerden elde edilen algoritma sonuçları, bulanık AHP kullanılarak karşılaştırılmıştır. Çalışmada uçaklar, maliyet, fiziksel nitelikler ve zaman gibi kriterler ve bunlara bağlı alt kriterlere göre listelenmiştir. Çalışmanın bulguları, uçak seçiminde sahip olunan fiziksel özelliklerin en önemli performans göstergesi olduğunu ortaya koymaktadır. Wei (2006), havaalanı iniş ücretlerinin havayollarının uçak büyüklüğü ve uçuş frekans kararlarını nasıl etkileyebileceğini oyun temelli model (game-theoretic model) aracılığıyla araştırmıştır. Bu kapsamda, havaalanı iniş ücretlerin yüksek ya da düşük olduğu senaryoların havayolu şirketlerinin maliyet, doluluk oranı, uçak seçimi, frekans sayısı ve filo yapısı gibi faktörlerini nasıl etkilediğini incelemiştir. Çalışmanın bulguları yüksek iniş ücretlerinin havayolu şirketlerini; geniş gövdeli uçak seçimine, daha yüksek doluluk oranı ile uçuş gerçekleştirmeye ve frekans sayısının buna bağlı olarak azaltılmasına zorladığını göstermiştir. Givoni ve Rietveld (2009), dünyanın farklı uçuş noktalarında uçak seçiminde hangi faktörlerin belirleyici olduğunu incelemiştir. Bu kapsamda ABD, Avrupa ve Asya'da 500'den fazla rota üzerinde uçak seçiminin belirleyicilerini regresyon analizi kullanarak araştırmıştır. Çalışmanın sonuçları, uçak seçiminin esas olarak rota özelliklerinden önemli ölçüde etkilendiğini ve havalimanın özelliklerinin bunda etkili olmadığını göstermiştir.

\section{Yöntem}

\subsection{TOPSIS Yöntemi}

TOPSIS yöntemi, ilk olarak Hwang ve Yoon'un (1981) tarafından geliştirilmiş olup, çok kriterli karar verme yöntemlerinden birdir. Bu yöntem kullanılarak alternatif seçeneklerin belirli kriterler doğrultusunda ve kriterlerin alabileceği maksimum ve minimum değerler arasında ideal duruma göre karşılaştırılması gerçekleştirilmektedir. Dolayısıyla TOPSIS yöntemi, ölçütlerin tüm en iyi değerlerinin bileşiminden oluşan pozitif ideal çözümler ile en kötü değerlerinin bileşiminden oluşan negatif ideal çözümlerin olduğu çok ölçütlü karar verme problemini çözerken seçilen alternatifin pozitif ideal çözümden en kısa mesafede ve negatif ideal çözümden en uzak mesafede bulunması anlayışına dayanmaktadır (Yurdakul \& İç, 2003, s. 11; Özdağoğlu, 2012, s. 550). TOPSIS yönteminin uygulanması 6 adımdan oluşan bir çözüm sürecini içermektedir. Aşağıda sözü edilen adımlara yer verilmektedir (Demireli, 2010, s. 104106; Alp \& Engin, 2011, s. 68-73; Supçiller \& Çapraz, 2011, s. 9-12; Şimşek, Çatır, \& Ömürbek, 2015, s. 140-142; Uygurtürk \& Korkmaz, 2012, s. 103-105).

\section{Adım: Karar Matrisinin Oluşturulması}

Karar matrisinin satırlarında alternatifler, sütunlarında ise kriterler yer almaktadır. Buna göre A karar matrisinde $m$ tane alternatif ve $n$ tane kriter bulunmaktadır. Başlangıç matrisi olarak kabul edilen A matrisi karar verici tarafından belirlediği alternatif ve kriterler esas alınarak oluşturulur. A karar matrisinin gösterimi aşağıdaki gibidir:

$A_{i j}=\left[\begin{array}{cccc}a_{11} & a_{12} & \cdots & a_{1 n} \\ a_{21} & a_{22} & \cdots & a_{2 n} \\ \vdots & \vdots & \ddots & \vdots \\ a_{m 1} & a_{m 2} & \cdots & a_{m n}\end{array}\right]$

$A_{i j}$ matrisinde, $m$ karar noktası sayısını, $n$ değerlendirme faktörü sayısını göstermektedir. 
2. Adım: Normalize Edilmiş Karar Matrisinin (R) Oluşturulması

A karar matrisinde bulunan veriler kullanılarak normalize edilmiş karar matrisi $(R)$ hesaplanmaktadır. Karar matrisinde yer alan kriterlere ait puan veya özelliklerin kareleri toplamının karekökü alınarak matris normalize edilir. Normalize edilmiş karar matrisine $(R)$ ilişkin formül aşağıdaki gibidir:

$r_{i j}=\frac{a_{i j}}{\sqrt{\sum_{i=1}^{m} a_{i j}^{2}}}$

$i=1,2, \ldots \ldots, n$

ve

Elde edilen normalize edilmiş karar matrisi ise aşağıdaki gibi gösterilebilir:

$R_{i j}=\left[\begin{array}{cccc}r_{11} & r_{12} & \cdots & r_{1 n} \\ r_{21} & r_{22} & \cdots & r_{2 n} \\ \vdots & \vdots & \ddots & \vdots \\ r_{m 1} & r_{m 2} & \cdots & r_{m n}\end{array}\right]$

3. Adım: Ağırlıklı Standart Karar MatrisininOluşturulması

Ağırlıklı standart karar matrisi oluşturulurken ilk olarak değerlendirme kriterlerinin ağırlık değerleri olan $w_{i}$ değeri hesaplanır. Kriterlerin ağırlık değerleri belirlenirken bunların toplamının 1'e eşit olması gerekmektedir. Bundan sonraki aşamada matrisinin her bir sütunundaki eleman ilgili ağırlık değeri olan $w_{i}$ ile çarpılarak $V$ matrisi oluşturulur. Ağırlıklı standart karar matrisinin ( $V$ gösterimi aşağıdaki gibidir:

$v_{i j}=r_{i j} \cdot w_{i j}$

$V_{i j}=\left[\begin{array}{cccc}w_{1} r_{11} & w_{2} r_{12} & \cdots & w_{n} r_{1 n} \\ w_{1} r_{21} & w_{1} r_{11} & \cdots & w_{n} r_{2 n} \\ \vdots & \vdots & \ddots & \vdots \\ w_{1} r_{m 1} & w_{2} r_{m 2} & \cdots & w_{n} r_{m n}\end{array}\right]$

4. Adım: Pozitif İdeal $\left(\mathrm{A}^{+}\right)$ve Negatif İdeal $\left(\mathrm{A}^{-}\right)$Çözümlerin Oluşturulması

Pozitif İdeal $\left(\mathrm{A}^{+}\right)$ve Negatif İdeal $\left(\mathrm{A}^{-}\right)$çözümleri oluşturulurken pozitif ideal çözüm, ağırlıklı standart karar matrisinin en iyi performans değerlerinden oluşturulur. Negatif ideal çözüm ise en kötü performans değerlerinden yaratılır. Pozitif ve negatif ideal çözümlere ilişkin formüller aşağıdaki gibidir:

$\mathrm{A}^{+}=\left\{v_{1}^{+}, v_{2}^{+}, \ldots, v_{1}^{+}\right\}$(maksimum değerler)

$\mathrm{A}^{-}=\left\{v_{1}^{-}, v_{2}^{-}, \ldots, v_{1}^{-}\right\}$(minimum değerler)

5. Adım: Ayırım Ölçülerinin Hesaplanması

Ayırım ölçülerinin hesaplanırken her bir alternatife ilişkin ölçüt değerinin pozitif ideal ve negatif ideal çözüm setinden uzaklıklarının belirlenmektedir. Buradan elde edilen alternatiflere ilişkin uzaklık değerleri ise pozitif ideal çözüme uzaklık $\left(\mathrm{S}^{+}\right)$ve negatif ideal çözüme uzaklık $\left(\mathrm{S}^{-}\right)$şeklinde gösterilmektedir. Maksimum ve minimum ideal noktalara olan uzaklık değerleri aşağıdaki formüller yardımıyla hesaplanmaktadır:

$\begin{array}{ll}\mathrm{S}^{+}=\sqrt{\sum_{j=1}^{n}\left(v_{i j}-v_{j}^{+}\right)^{2}} & i=1,2, \ldots, m \\ \mathrm{~S}^{-}=\sqrt{\sum_{j=1}^{n}\left(v_{i j}-v_{j}^{-}\right)^{2}} & i=1,2, \ldots, m\end{array}$

Burada hesaplanacak olan $S_{i}^{+}$ve $S_{i}^{-}$sayısı karşılaştırılan alternatif sayısı kadardır. 


\section{Ideal Çözüme Göreli Yakınlığın Hesaplanması}

Her bir alternatifin ideal çözüme göreli yakınlığı olan $C^{+}$hesaplanmasında için bir önceki adımda bulunan $\mathrm{S}^{+}$ve $\mathrm{S}^{-}$değerleri kullanılır. Burada kullanılan esas ölçüt, negatif ideal ayırım ölçüsünün toplam ayırım ölçüsü içindeki payıdır. İdeal çözüme göreli yakınlık aşağıdaki formül aracılıyla hesaplanabilir:

$C_{i}^{+}=\frac{S_{i}^{+}}{S_{i}^{-}+S_{i}^{+}} \quad i=1,2, \ldots, m$

Formülde yer alan $C_{i}^{+}$değeri $0 \leq C_{i}^{+} \leq 1$ arasında değer almaktadır. Buna ek olarak $C_{i}^{+}=1$ olması karar noktasının ideal çözüme yakın olduğunu, $C_{i}^{-}=0$ olması ise, karar noktasının negatif ideal çözüme noktasında bulunduğunu göstermektedir.

\section{TOPSIS Yöntemi ỉle Uçak Seçimi}

Havayolları için ticari uçak seçimi probleminin çözümünde atılması gereken ilk adım seçim kriterlerinin ve alternatif uçak tiplerinin belirlenmiş olmasıdır. ilk olarak havayolu endüstrisinde akademik ve/veya sektörel tecrübeye sahip toplam 8 uzman desteğinden yararlanılarak Tablo 1'de yer alan seçim kriterleri belirlenmiştir. Kriterlerin ağırlıklarının belirlenmesinde kullanılacak veriler aynı uzmanların verdikleri ağırlık puanları ve değerlendirmeleri sonucu elde edilmiştir.

Tablo 1. Elde edilmiş Seçim Kriterleri

Kriter Birim

Menzil Deniz mili

Fiyat Milyon \$

Hız Knot

Yolcu Kapasitesi

Taşınabilen yolcu sayısı

Yakıt tüketimi

Dolar / Mil

Tablo 1'de en uygun hava aracı seçimi için seçim kriterlerine yer verilmektedir. Buna göre belirlenen kriterler, menzil, fiyat, hız, yolcu kapasitesi ve yakıt tüketimi şeklinde sıralanmaktadır. Çalışmanın bu kısmında belirlenen seçim kriterlerinin tercih edilme nedeni ve havayolları açıcından önemine sırasıyla yer verilecektir.

Uçak menzili; uçakların etkili hizmet verebileceği azami mesafeyi göstermesi bakımından oldukça önem taşımaktadır. Havayolu şirketleri, sahip oldukları uçuş trafiğine ve uçuş ağlarına bağlı olarak kendilerine en uygun menzile sahip uçakları tercih etmektedir. Genel itibariyle okyanus aşırı uçuş gerçekleştiren havayolu firmaları, uzun menzile sahip havaaraçlarını tercih etmektedir. Bölgesel uçuş gerçekleştiren havayolu şirketleri ise kısa menzile sahip uçakları kullanmaktadır.

Havaaracı fiyatı; havayolu firmaları açısından satın alma kararını etkileyen en önemli kriterlerden biridir. Havayolu şirketlerinin maliyet yapısı incelendiğinde, satın alma giderleri ve havaaracı fiyatlarının oldukça yüksek olduğu görülmektedir. Havayolu şirketleri kendileri açısından belirlenen özelliklere sahip havaaraçlarını, en düşük fiyattan elde etme eğilimindedir. Dolayısıyla, havayolu şirketleri, beklentilerini karşılayacak benzer özelliklere sahip iki uçak arasında seçim yaparken düşük maliyetli olanı tercih edecektir.

Havaaracı hızı; diğer taşıma modlarıyla karşılaştırıldığında havayolunun en önemli tercih sebebi, en hızlı ulaşım alternatifi olmasıdır. Havayolu şirketleri, uçak seçiminde 
bulunurken daha fazla uçuş gerçekleştirmek, uçuş frekans sayısını arttırmak ve müşteri ihtiyaçlarını karşılamak amacıyla hava aracının hızını da dikkate alacaktır. Buna ek olarak, özellikle uzun mesafeli uçuşlarda havaaraçlarının hızı, uçuş süresini dikkate değer biçimde etkilemektedir. Dolaysıyla, uçak seçiminde havaaraçlarının hızı temel belirleyiciler arasında gösterilebilir.

Yolcu kapasitesi; bir diğer önemli seçim kriteri ise havaaraçlarının koltuk kapasitesidir. Havayolları firmaları açısından uçağın dolu olarak uçması ve doluluk oranının yüksek olması gelirleri arttırıcı önemli faktörler arasında gösterilebilir. Buna ek olarak koltuk kapasitesi fazla olan havaaraçlarının tercih edilmesi hem birim maliyeti düşürücü hem de geliri artırıcı bir etkiye sahiptir. Dolayısıyla, benzer maliyet ve teknik özelliklere sahip uçaklar içerisinde daha fazla koltuk kapasitesine sahip olan uçağın tercih edilmesi muhtemeldir.

Yakıt tüketimi; havaaracı seçiminde temel alınması gereken en önemli kriterlerden birinin de yakıt tüketimi olduğu görülmektedir. Havayollarının operasyon giderleri dikkate alındığında yakıt giderlerinin en önemli kalemlerden biri olduğu görülmektedir. Nitekim Vasigh vd., göre (2012, s. 31) yakıt giderleri, havayolu firmaları açısından faaliyet giderlerinin en önemli bileşenlerinden bir olup toplam içerisindeki payı \%30 dolaylarındadır. Dolayısıyla uçak seçiminde havayolu firmalarının dikkate alması gereken en önemli unsurlardan biri de havaaraçlarının yakıt maliyetleridir.

Seçim kriterlerinin belirlenmesinden sonra kısa ve orta mesafeli uçuşlara uygun karar alternatifleri belirlenmiştir. Karar alternatiflerinin belirlenmesinde kullanılan yöntem, havaaraçlarına olan talep ve onların sipariş tutarlarıdır. Nitekim yapılan araştırmalar sonucunda kısa ve orta mesafeli uçuşlara uygun, 2016 yılında en çok sipariş edilen havaaraçlarının A320, A321, B737-800 ve B737-900ER tipi uçaklar olduğu belirlenmiştir. Havayolu işletmeleri için kısa ve orta mesafeli uçuşlarda kullanılabilecek en uygun uçak seçiminin hangisi olduğuna çok kriterli ampirik yöntemlerden TOPSIS metodu kullanılarak karar verilmiştir.

\subsection{TOPSIS ile Uçak Seçimi Uygulaması}

Karar Matrisinin Oluşturulması: TOPSIS yönteminin uygulanmasında ilk adımı karar matrisinin oluşturulmasıdır. Havaaracı seçimiyle ilgili olarak karar matrisinde menzil, fiyat, hız, yolcu kapasitesi ve yakıt tüketimi kriterleri dikkate alınmıştır. Alternatifler arasında ise A320, A321, B737-800 ve B737-900ER modelleri görülmektedir. Karar matrisi eşitlik (1) de yer aldığı şekilde kurulmakta birlikte Tablo 2'de görülmektedir.

Tablo 2. Elde Edilmiş Karar Matrisi

$\begin{array}{lr}\text { A320 } & \text { Menzil } \\ \text { A321 } & 3300 \\ \text { B737-800 } & 3200 \\ \text { B737-900ER } & 3115 \\ & 3200\end{array}$

$\begin{array}{cc}\text { Fiyat } & \text { HIz } \\ 98 & 444 \\ 114,9 & 444 \\ 79 & 472 \\ 85 & 472\end{array}$

Yolcu kapasitesi
$\begin{gathered}180 \\ 236 \\ 189 \\ 215\end{gathered}$

Yakıt tüketimi
13,7
14,88
13,24
14,69

Normalize Edilmiş Karar Matrisinin (R) Oluşturulması: Alternatiflere ait skorların belirli bir birime çevrilmesi amacıyla gerçekleştirilen normalizasyon işleminde eşitlik (2)'den yararlanılmaktadır. Elde edilen normalize değerler aşağıda görülmektedir (Tablo 3). 
Tablo 3. Normalize Edilmiş Matris

$\begin{array}{lccccc} & \text { Menzil } & \text { Fiyat } & \text { Hız } & \text { Yolcu kapasitesi } & \text { Yakıt tüketimi } \\ \text { A320 } & 0,514914 & 0,514565 & 0,484490 & 0,436510 & 0,484308 \\ \text { A321 } & 0,499310 & 0,603301 & 0,484490 & 0,572313 & 0,526022 \\ \text { B737-800 } & 0,486047 & 0,414802 & 0,515043 & 0,458336 & 0,468047 \\ \text { B737-900ER } & 0,499310 & 0,446306 & 0,515043 & 0,521387 & 0,519306\end{array}$

Ağırlıklı Standart Karar Matrisinin Oluşturulması: TOPSIS yönteminin üçüncü adımında bazı kriterlerin daha önemli olabileceğinde hareketle normalize değerler kriterlerin önem katsayıları ile çarpılarak ağırlıklandırılır. Eşitlik (3)' e bağlı olarak gerçekleştirilen ağırlıklandırma işlemi sonucu oluşan ağırıklandırılmış standart karar matrisi değerleri Tablo 4'de görülmektedir.

Tablo 4. AğırlıklandırılmışNormalize Matris

\begin{tabular}{|l|c|c|c|c|c|}
\hline \multicolumn{1}{|c|}{ Önem Katsayıları } & 0,135 & 0,245 & 0,100 & 0,200 & 0,320 \\
\hline A320 & Menzil & Fiyat & Hı & Yolcu kapasitesi & Yakıt tüketimi \\
\hline A321 & 0,069513 & 0,126068 & 0,048449 & 0,087302 & 0,154979 \\
\hline B737-800 & 0,067407 & 0,147809 & 0,048449 & 0,114463 & 0,168327 \\
\hline B737-900ER & 0,065616 & 0,101627 & 0,051504 & 0,091667 & 0,149775 \\
\hline
\end{tabular}

Pozitif ideal $\left(\mathbf{A}^{+}\right)$ve Negatif İdeal $\left(\mathbf{A}^{-}\right)$Çözümlerin Oluşturulması: Bu adımda karar alternatiflerinin pozitif ideal ve negatif ideal karar noktasına olan uzaklıkları eşitlik (4) ve eşitlik (5) kullanılarak hesaplanır. Burada fiyat ve yakıt tüketimi kriterleri maliyet (faydasız) kriterleri olduğu için diğer kriterlerden farklı olarak pozitif ideal değerlerde minimum değerler, negatif ideal değerlerde ise maksimum değerler işleme alınmıştır. Her bir kriter için pozitif ideal ve negatif ideal çözüm değerleri Tablo 5' de gösterilmektedir.

Tablo 5. Pozitif İdeal ve Negatif İdeal Çözüm Değerlerinin Elde Edilmesi

\begin{tabular}{|l|l|l|l|l|l|}
\hline Pozitif İdeal Çözüm Değerleri & $\mathbf{0 , 0 6 9 5 1 3}$ & $\mathbf{0 , 1 0 1 6 2 7}$ & $\mathbf{0 , 0 5 1 5 0 4}$ & $\mathbf{0 , 1 1 4 4 6 3}$ & $\mathbf{0 , 1 4 9 7 7 5}$ \\
\hline Negatif İdeal Çözüm Değerleri & 0,065616 & 0,147809 & 0,048449 & 0,087302 & 0,168327 \\
\hline
\end{tabular}

Ayırım Ölçülerinin Hesaplanması: Bu adımda havaaraçlarına ait pozitif ideal ve negatif ideal çözüm değerleri kullanılarak sırasıyla pozitif ve negatif ideal çözüme uzaklık değerleri belirlenir. Eşitlik (6) ve eşitlik (7) yardımıyla gerçekleştirilen bu adımda elde edilen pozitif ideal ve negatif ideal ayırım ölçüleri aşağıda gösterilmektedir(Tablo 6).

Tablo 6. Pozitif İdeal ve Negatif İdeal Uzaklıkların Elde Edilmesi

\begin{tabular}{|l|c|c|c|c|c|c|c|}
\hline & Menzil & Fiyat & Hız & Yolcu kapasitesi & Yakıt tüketimi & Toplam & \multicolumn{1}{|c|}{$\mathbf{S}^{*}$} \\
\hline A320 & 0,000000 & 0,000597 & 0,000009 & 0,000738 & 0,000027 & 0,001372 & 0,037034 \\
\hline A321 & 0,000004 & 0,002133 & 0,000009 & 0,000000 & 0,000344 & 0,002491 & 0,049907 \\
\hline B737-800 & 0,000015 & 0,000000 & 0,000000 & 0,000520 & 0,000000 & 0,000535 & 0,023126 \\
\hline B737-900ER & 0,000004 & 0,000060 & 0,000000 & 0,000104 & 0,000269 & 0,000437 & 0,020900 \\
\hline & Menzil & Fiyat & Hız & Yolcu kapasitesi & Yakıt tüketimi & Toplam & Si \\
\hline A320 & 0,000015 & 0,000473 & 0,000000 & 0,000000 & 0,000178 & 0,000666 & 0,025807 \\
\hline A321 & 0,000003 & 0,000000 & 0,000000 & 0,000738 & 0,000000 & 0,000741 & 0,027220 \\
\hline B737-800 & 0,000000 & 0,002133 & 0,000009 & 0,000019 & 0,000344 & 0,002505 & 0,050054 \\
\hline B737-900ER & 0,000003 & 0,001479 & 0,000009 & 0,000288 & 0,000005 & 0,001785 & 0,042247 \\
\hline
\end{tabular}


İdeal Çözüme Göreli Yakınlığın Hesaplanması: İdeal çözüme göreli yakınlığın hesaplanmasında ise; bir önceki adımda elde edilen negatif ideal çözüm değerlerinin, kendi değeri ve aynı sütundaki alternatifin pozitif ideal çözüm değerlerinin toplamına bölünmesiyle elde edilen değerler Tablo 7'de gösterilmektedir

TOPSIS yönteminin son adımında her bir alternatife ilişkin göreli yakınlık değeri yardımıyla sıralama işlemi yapılır. Buna göre ideal çözüme en yakın karar alternatifleri eşitlik (8) yardımıyla hesaplanmaktadır. Elde edilen $\mathrm{Ci}^{*}$ değerlerinin büyükten küçüğe doğru sıralanması ile alternatiflerin öncelik sıralaması elde edilmiş olur. Yöntem sonucunda elde edilen sıralama Tablo 7'de görülmektedir.

Tablo 7. İdeal Çözüme Göreli Yakınlığın Hesaplanması

\begin{tabular}{|l|c|c|c|}
\hline Alternatif & $\mathbf{S}_{\mathbf{i}}^{*}$ & $\mathbf{S i}^{-}$ & $\mathbf{C}_{\mathbf{i}}{ }^{\mathbf{*}}$ \\
\hline A321 & 0,0370340 & 0,0258072 & 0,4106736 \\
\hline A320 & 0,0499074 & 0,0272196 & 0,3529189 \\
\hline B737-800 & 0,0231262 & 0,0500537 & 0,6839811 \\
\hline B737-900ER & 0,0208999 & 0,0422467 & 0,6690261 \\
\hline
\end{tabular}

Tablo 7'de verilen değerler incelendiğinde $\left(C_{i}^{*}\right)$ değerlerinin büyükten küçüğe doğru sıralanmasıyla en uygun uçak tipi belirlenmiş olur. Dolayısıyla TOPSıS yöntemi sonucu elde edilen bulgular havayolu şirketleri açısında belirlenen kriterlere en uygun uçak tipinin "B737-800" olduğunu göstermektedir. TOPSiS yöntemi, ikinci en iyi alternatifin B737-900ER uçak tipi olduğunu göstermektedir.

\section{Sonuç}

Havayolu taşımacılığında rekabetin ve havaaracı maliyetlerinin giderek artması, ekonomik koşullara oldukça duyarlı olan havayolu firmalarını mevcut kaynakların en uygun şekilde kullanılmaya zorlamaktadır. Mevcut kaynakların optimum düzeyde kullanan firmalar, sektörde yaşanan yıkıcı rekabetten ve mevcut veya olması muhtemel ekonomik dalgalanmalardan minimum düzeyde etkilenebilir. Bu kapsamda havayolu şirketleri açısında en kritik kararlarında biri de yeni hani havaaracı satın alınması ve seçimi ile ilgili aşamalardır. Bu çalışmada, kısa ve orta mesafeli havayolu taşımacılığında kullanılmak üzere, satın alınacak en uygun havaaracı tipinin belirlenmesi hedeflenmektedir. Bu doğrultuda havaaracı seçim kriterleri ve ağırlıklandırmaları havacılık endüstrisi uzmanları tarafından belirlenmiştir. Belirlenen kriterler doğrultusunda seçilmiş karar alternatifleri üzerinde TOPSIS yöntemleri uygulanarak en uygun uçak tipinin belirlenmesi amaçlanmıştır. Çalışmada kısa ve orta mesafeli uçuşlarda kullanılabilecek, 2016 yılında en çok sipariş edilen havaaraçları olan A320, A321, B737-8 ve B737-900ER uçak tipleri karar alternatifi olarak belirlenmiştir. TOPSIS yöntemi kullanılarak ampirik olarak incelenen 4 uçak tipi arasında, belirlenen kriterlere göre havayolu firmaları açısından en uygun uçak tipinin hangisi olduğu belirlenmeye çalışılmıştır. Çalışmanın bulguları TOPSıS yöntemi kullanılarak belirlenen en uygun uçak tipinin B737-800 olduğunu göstermektedir. B737-800'den sonra en uygun alternatifin B737-900ER olduğu görülürken üçüncü sırada A321 ve son sırada ise A320 tipi uçak gelmektedir. Çalışmanın belirlenen kriterler ve uçak tipi alternatifleri esas alındığında havayolu şirketlerine havaaracı seçimi konusunda yol gösterici olması beklenmektedir. Çalışma aynı zamanda, havayolu firmalarına belirlenen kriterleri kendi öncelikleri ölçüsünde 
ağırlıklandırmaları sonucu beklentilerine uygun uçak tipinin seçiminde alternatif bir model olarak önerilmektedir. Bu çalışmada uygulanan yöntemler dikkate alındığında farklı kriterlerin veya farklı uçak tiplerinin ilave edilmesiyle farklı sonuçların elde edilmesi beklenebilir. Dolaysıyla havayolu firmaları kendi uçuş ağı ve önceliklerine göre farklı hava araçları arasında bu yöntemleri kullanarak en uygun uçaklar seçebilir. Çalışmanın bu açıdan havayolu firmalarına katkı sağlaması beklenmektedir

\section{KAYNAKÇA}

Alp, 5., \& Engin, T. (2011). Trafik kazalarının nedenleri ve sonuçları arasındaki ilişkinin topsis ve ahp yöntemleri kullanılarak analizi ve değerlendirilmesi. İstanbul Ticaret Üniversitesi Fen Bilimleri Dergisi, 10(19), 65-87.

Bhadra, D. (2003). Choice of aircraft fleets in the US NAS: findings from a multinomial logit analysis. In Paper to be presented at the 3rd ATIO/AIAA conference.

Bruno, G., Esposito, E., \& Genovese, A. (2015). A model for aircraft evaluation to support strategic decisions. Expert Systems with Applications, 42-13, 5580-5590.

Demireli, E. (2010). TOPSIS çok kriterli karar verme sistemi: Türkiye'deki kamu bankaları üzerine bir uygulama. Girişimcilik ve Kalkınma Dergisi, 5(1), 101-112.

Dožić, S., \& Kalić, M. (2014). An AHP approach to aircraft selection process. Transportation Research Procedia, 3, 165-174.

Dožić, S., \& Kalić, M. (2015). Comparison of two MCDM methodologies in aircraft type selection problem. Transportation Research Procedia, 10, 910-919.

Givoni, M., \& Rietveld, P. (2009). Airline's choice of aircraft size-Explanations and implications. Transportation Research Part A: Policy and Practise, 43(5), 500-510.

Givoni, M., \& Rietveld, P. (2010). The environmental implications of airlines' choice of aircraft size. Journal of Air Transport Management, 16(3), 159-167.

Gomes, L. F. A. M., Mattos Fernandes, J. E., \& Mello, J. C. C. (2014). A fuzzy stochastic approach to the multicriteria selection of an aircraft for regional chartering. Journal of Advanced Transportation, 48(3), 223-237.

Harasani, W. I. (2006). Evaluation and Selection of a Fleet of Aircraft for a Local Airline. Journal of King Abdulaziz University: Engineering Sciences, 17(2), 3-16.

Khoo, H. L., \& Teoh, L. E. (2014). An optimal aircraft fleet management decision model under uncertainty. Journal of Advanced Transportation, 48(7), 798-820.

Listes, O., \& Dekker, R. (2005). A scenario aggregation-based approach for determining a robust airline fleet composition for dynamic capacity allocation. Transportation Science, 39(3), 367382.

Sherali, H. D., Bish, E. K., \& Zhu, X. (2006). Airline fleet assignment concepts, models, and algorithms. European Journal of Operational Research, 172(1), 1-30.

Özdağoğlu, A. (2012). Üretim Yapan Isletmeler için Hidrolik Giyotin Alternatiflerinin TOPSIS Yöntemi ile Incelenmesi. Ege Akademik Bakış, 12(4), 549-562.

Özdemir, Y., Başlıgil, H., \& Karaca , M. (2011). Aircraft Selection Using Analytic Network Process: A Case for Turkish Airlines. World Congress on Engineering. Londra. http://www.iaeng.org/publication/WCE2011/WCE2011_pp1155-1159.pdf adresinden alındı

Özdemir, Y., \& Başlıgil, H. (2016). Aircraft selection using fuzzy ANP and the generalized choquet integral method: The Turkish Airlines case. Journal of Intelligent\& Fuzzy Systems, 31(1), 112.

Supçiller, A. A., \& Çapraz, O. (2011). AHP-TOPSIS Yöntemine Dayali Tedarikçi Seçimi Uygulaması. İstanbul Üniversitesi Iktisat Fakültesi Ekonometri ve İstatistik Dergisi(13), 1-22.

Şimşek, A., Çatır, O., \& Ömürbek, N. (2015). TOPSIS ve MOORA Yöntemleri ile Tedarikçi Seçimi: Turizm Sektöründe Bir Uygulama. Balıkesir Üniversitesi Sosyal Bilimler Enstitüsü Dergisi, 18(33), 133-161.

Teoh, L. E., \& Khoo, H. L. (2015). Airline Strategic Fleet Planning Framework. Journal of the Eastern Asia Society for Transportation Studies, 11, 2258-2276. 
Uygurtürk, H., \& Korkmaz, T. (2012). Finansal performansın TOPSıS çok kriterli karar verme yöntemi ile belirlenmesi: Ana metal sanayi işletmeleri üzerine bir uygulama. Eskişehir Osmangazi Üniversitesi İktisadi ve İdari Bilimler Dergisi, 7(2), 95-115.

Vasigh, B., Fleming, K., \& Tacker, T. (2012). Foundations of Airline Finance: Methodology and Practice. Furnham: Ashgate Publishing Company.

Wang, T. C., \& Chang, T. H. (2007). Application of TOPSIS in evaluating initial training aircraft under a fuzzy environment. Expert Systems with Applications, 33(4), 870-880.

Wei, W. (2006). Impact of landing fees on airlines' choice of aircraft size and service frequency in duopoly markets. Journal of Air Transport Management, 12(6), 288-292.

Yurdakul, M., \& İç, Y. T. (2003). Türk Otomotiv Firmalarının Performans Ölçümü ve Analizine Yönelik TOPSIS Yöntemini Kullanan Bir Örnek Çalışma. Gazi Üniversitesi Sosyal Bilimler Dergisi, 18(1), $1-18$. 